\title{
Matrix protein CCN1 induced by bacterial DNA and CpG ODN limits lung inflammation and contributes to innate immune homeostasis
}

\author{
H-G Moon ${ }^{1}$, Z Qin ${ }^{2}$, T Quan ${ }^{2}, \mathrm{~L} \mathrm{Xie}^{3}$, CS Dela Cruz ${ }^{4}$ and Y Jin ${ }^{1}$
}

To defend against pulmonary infections, lung epithelial cells are equipped with complex innate immunity closely linked to inflammation. Dysregulated innate immunity/inflammation leads to self-perpetuating lung injury. The CpG motif in bacterial DNA is one of the factors involved in bacterial infection-associated inflammation. Bacterial DNA and synthetic CpG oligonucleotide (ODN) induced CCN1 secretion from lung epithelial cells, functioning as a potential "braking" signal to prevent uncontrolled inflammatory responses. CpG ODN-induced endoplasmic reticulum (ER) stress resulted in Src-Y527 phosphorylation (pY527) and Src/CCN1 vWF domain dissociation. Src-Y527 activated caveolin-1 (cav-1) phosphorylation at Y14 and then modulated CCN1 secretion via pCav-1 interaction with the CCN1 IGFbp domain. Functionally, secreted CCN1 promoted anti-inflammatory cytokine interleukin (IL)-10 release from epithelial cells via integrin $\alpha$ V $36-P K C$, and this subsequently suppressed tumor necrosis factor (TNF)- $\alpha$, macrophage inflammatory protein 2 (MIP-2)-2 secretion and neutrophil infiltration in the lungs. Collectively, bacterial DNA/CpG ODN-stimulated CCN1 secretion via the BiP/GRP78-Src(Y527)-JNK-Cav-1(Y14) pathway and CpG-induced CCN1 conferred anti-inflammatory roles. Our studies suggested a novel paradigm by which the lung epithelium maintains innate immune homeostasis after bacterial infection.

\section{INTRODUCTION}

Lung epithelial cells are essential component of the airway physiological barrier and the first-line innate immunity to microbial pathogens. ${ }^{1,2}$ One of the most important innate immune function of lung epithelial cells is to recruit immune cells to the lung microenvironment to maintain homeostasis. ${ }^{1,2}$ Lung epithelial cells directly recognize the pathogen-associated molecular patterns via Toll-like receptors (TLRs) to initiate and amplify the innate immune responses needed for pathogen clearance during infection. ${ }^{3,4}$ Unmethylated CpG motifs are mostly present in bacterial DNA but not in human genomic DNAs. $^{5-8}$ CpG motifs in oligodeoxynucleotides (ODNs) activate host innate and acquired immune responses via TLR9 receptor-mediated mitogen-activated protein kinases and NFKB pathways, not only in immune cells but also in epithelial cells. ${ }^{5-7}$ The innate immunity is closely linked to inflammatory responses that include robust release of inflammatory cytokines/chemokines, which have a crucial role in bactericidal effects. ${ }^{9,10}$ However, dysregulated innate immunity and inflammatory responses can lead to damage of lung parenchyma, resulting in acute lung injury and contributing to significant mortality and morbidity. ${ }^{11}$ Therefore, a self-limiting or "braking" system in host epithelium is needed to prevent this 'runaway' inflammation and maintain lung microenvironment homeostasis after microbial infections.

The interleukin (IL)-10 family cytokines derived from immune cells and lung epithelial cells are essential for maintaining the integrity and homeostasis of lung epithelium via limiting the lung injury caused by bacterial infectionassociated inflammation. ${ }^{12,13}$ For example, the neutrophil counts in bronchoalveolar lavage fluid (BALF) and blood are much higher in IL-10 KO mice than wild-type mice. Furthermore, neutrophil infiltration and excessive inflammation are found in IL-10 KO mice, suggesting that the high 
mortality in IL-10 $\mathrm{KO}$ mice is associated with exaggerated inflammation. ${ }^{14}$ However, in a model of pre-existing sepsis followed by Pseudomonas aeruginosa pneumonia ("two-hit" model), inhibition of IL-10 improved survival and clearance of bacteria, ${ }^{15}$ suggesting a central role of IL-10 in the fine balance of bactericidal/innate immunity and tissue-damaging inflammation. ${ }^{16}$ Therefore, it is important to understand the regulatory machinery on lung epithelial cell-mediated homeostasis and innate immunity in response to bacterial infection. In our current report, we investigated a novel paradigm on how lung epithelial cells self-limit the potential "runaway" inflammation after bacterial infection via the regulation of proinflammatory and immunosuppressive cytokines.

CCN1 (Cyr61) is an immediate-early-response gene product ubiquitously expressed in lung cells, particularly in lung epithelial cells. ${ }^{17-20} \mathrm{CCN} 1$ is secreted into the extracellular matrix after stimulation by various stimuli and exhibits diverse cellular functions in a paracrine/autocrine manner. ${ }^{18} \mathrm{CCN} 1$ has diverse roles such as cell repair, tissue remodeling, cell migration, differentiation, proliferation, apoptosis, and senescence. ${ }^{18}$ Studies in animal models have confirmed that disruption of CCN1 is embryonic lethal ${ }^{21}$ and deregulation of $\mathrm{CCN} 1$ is involved in various pathologies related to inflammation and tissue repair. ${ }^{18}$ However, despite ubiquitous expression in lung parenchyma, its secretion and function in lung diseases remain unexplored. Our current studies investigated the secretion and function of $\mathrm{CCN} 1$ in response to bacterial infection. We further delineated the pathways involved in CCN1 secretion and the underlying mechanisms by which $\mathrm{CCN} 1$ confers its cellular and protective functions in lung epithelial cells during infection.

\section{RESULTS}

\section{Bacterial DNA and its synthetic motif CpG ODN induced} CCN1 secretion from lung epithelial cells

In vivo studies initially demonstrated that intranasal Klebsiella pneumoniae ( $10^{3} \mathrm{CFU}$ per mouse) infection rapidly increased CCN1 release in BALF and peaked around $24 \mathrm{~h}$ after stimulation (Figure 1a). We also stimulated the lung epithelial cells using bacterial genomic DNA obtained from K. pneumoniae, Acinetobacter bauminnii, and P. aerosinosa (Figure 1b). Bacterial DNAs rapidly augmented the CCN1 secretion from cultured Beas2B epithelial cells $4 \mathrm{~h}$ after stimulation (Figure 1b). Given the critical roles of TLRs in mediating lung bacterial infection and inflammation, we next assessed the effects of TLR agonists on CCN1 secretion in epithelial cells. Class C TLR9 agonist, CpG ODN 2395, induced a robust $\mathrm{CCN} 1$ secretion in three different epithelial cells, in a dose- and time-dependent manner (Figure 1c, Supplementary Figure S1A,B online). Unmethylated $\mathrm{CpG}$ dinucleotides are more frequent in the genomes of bacteria than of humans. ${ }^{22}$ CpG ODNs are synthetic unmethylated bacterial DNA motif containing CpG dinucleotides that activate TLR9-mediated pathways. ${ }^{23,24}$ We found that all three major classes of stimulatory CpG ODNs (ODN2336, 2006, and 2395) increased the CCN1 secretion (Supplementary Figure S1C) and class C expressed the strongest effects on induction of $\mathrm{CCN} 1$ secretion (Supplementary Figure S1C). Interestingly, although CpG ODNs are well-known TLR9 agonists, TLR9 silencing by short interfering RNA and inhibition of the NF- $\mathrm{KB}$ (nuclear factor kappa-light-chain-enhancer of activated B cells) pathway by Bay11-7082 had no significant effects on CCN1 secretion (Supplementary Figure S1D,E), suggesting that the $\mathrm{CpG}$ ODN-induced CCN1 secretion was TLR9-independent. To determine the temporal dynamics of CCN1 secretion from lung epithelial cells after bacterial DNA/CpG ODNs, we evaluated the $\mathrm{CCN} 1$ protein level at various time points by enzyme-linked immunosorbent assay. Majority of CCN1 were secreted within $1 \mathrm{~h}$ after ODN stimulation (Figure 1d). Furthermore, we collected the supernatant of Beas2B cells after stimulation with ODN. Exosome and soluble fraction were isolated using ultracentrifugation. We found that the majority of matrix CCN1 was secreted via soluble forms, rather than in exosome-encapsulated forms (Figure 1e). To test CpG ODNinduced CCN1 secretion in vivo, we delivered ODN 2395 intranasally to mice. Consistently, ODN 2395 enhanced CCN1 level in mouse BALF in a dose-dependent manner (Figure 1f). All the above observations supported that bacterial DNA/CpG ODN-stimulated CCN1 secretion from lung epithelial cells in soluble forms as an immediate early response to microbial infection/stimulation. These results prompted us to explore the functional roles of secreted CCN1 in lungs after bacterial infection.

\section{Bacterial DNA/CpG ODN-induced CCN1 secretion conferred anti-inflammatory effects both in vitro and in vivo}

To explore the functions of $\mathrm{CCN} 1$ in bacterial lung infectionassociated inflammation in vivo, we first used lipopolysaccharide (LPS)-induced inflammation model in mice. We administrated intranasally CCN1 or ODN with and without LPS. The CCN1 or ODN was delivered at the same time along with LPS, and BALF was collected after $24 \mathrm{~h}$. Differential cell counts including neutrophils and macrophages were conducted after Diff-Quick staining. We showed that co-treatment with either ODN or CCN1 with LPS attenuated the LPS-induced neutrophil infiltration, assessed by neutrophil count in BALF (Figure 2a) and lung tissue (Figure 2b). Macrophage inflammatory protein 2 (MIP-2), a chemokine that attracts neutrophils and normally has its secretion enhanced by bacterial infection-associated inflammation was also enhanced with LPS. However, this effect was abolished after addition of ODN or CCN1 (Figure 2c). Tumor necrosis factor (TNF)- $\alpha$ is a well-known inflammatory mediator of sepsisinduced lung injury. ${ }^{22,25}$ IL-10, on the contrary, represses pro-inflammatory responses in lungs. ${ }^{26}$ Both ODN and CCN1 suppressed LPS-induced TNF- $\alpha$, but upregulated the IL-10 level in BALF in both the absence or presence of LPS (Figure 2d). Furthermore, co-treatment of bioactive CCN1 recombinant protein reduced the LPS-induced TNF- $\alpha$ and IL- 6 secretions from alveolar macrophages in a dose-dependent manner (Supplementary Figure S2A). 

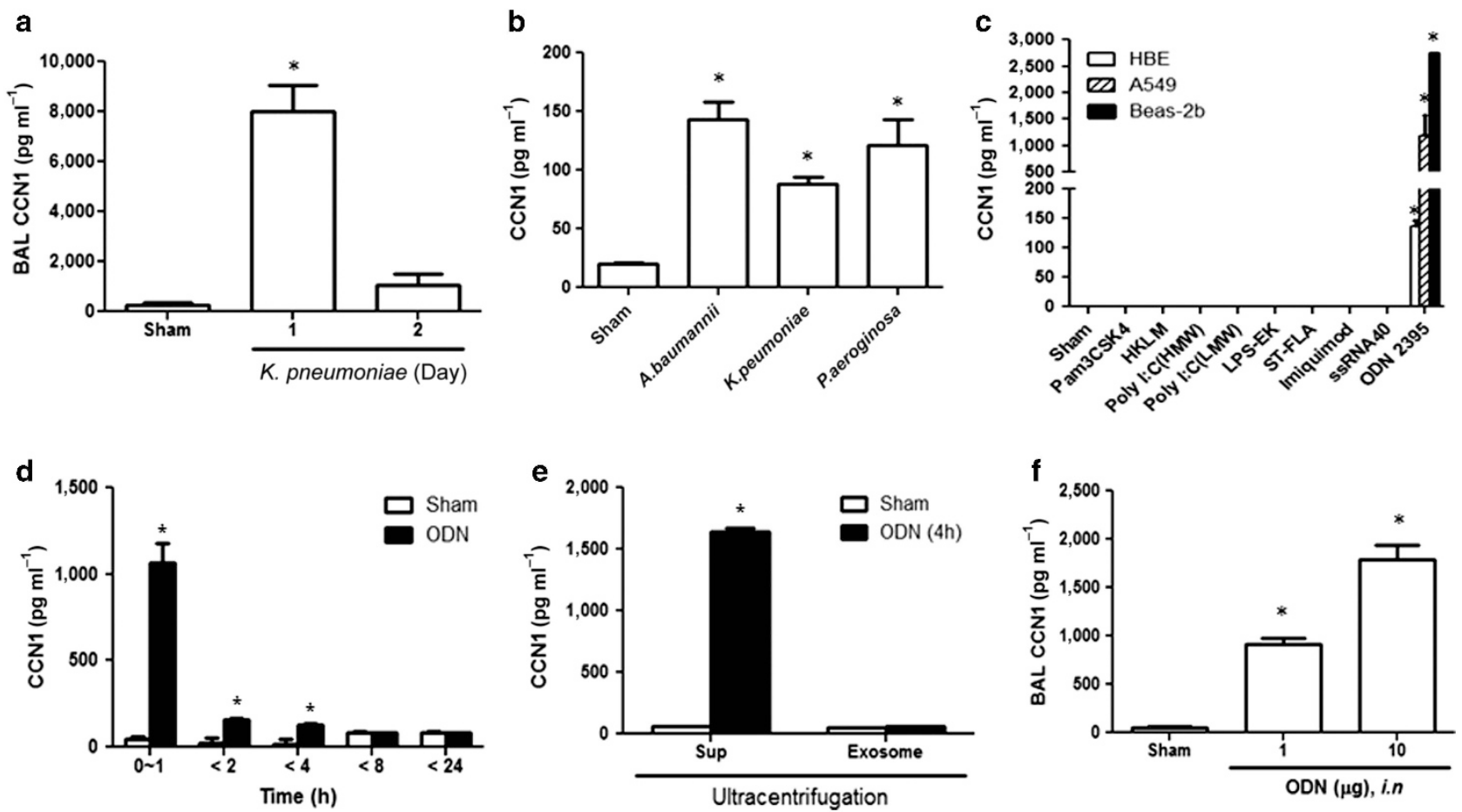

Figure 1 Bacterial DNA/CpG oligonucleotide (ODN) induced CCN1 secretion in lung epithelial cells. (a) Secreted CCN1 in bronchoalveolar lavage fluid (BALF) was measured using enzyme-linked immunosorbent assay (ELISA) after administration of $K$. pneumoniae (103 CFU per mouse) intranasally into C57/BL6 mice. (b) Beas2B cells were treated with bacterial DNAs $\left(1 \mu \mathrm{g} \mathrm{ml}{ }^{-1}\right)$. After $4 \mathrm{~h}, \mathrm{CCN} 1$ was measured using ELISA. (c) HBE, A549, and Beas2B cells were treated with Toll-like receptor (TLR) agonists. After $24 \mathrm{~h}$, the secreted CCN1 was measured using ELISA. Pam3CSK4 (1 $\left.\mu \mathrm{g} \mathrm{ml}{ }^{-1}\right), \mathrm{HKLM}(108$ cells $\left.\mathrm{ml}^{-1}\right)$, lipopolysaccharide (LPS)-EK $\left(1 \mu \mathrm{g} \mathrm{ml}^{-1}\right)$, ST-FLA $\left(1 \mu \mathrm{g} \mathrm{ml}^{-1}\right)$, FSL-1 $\left(1 \mu \mathrm{g} \mathrm{ml}^{-1}\right)$, and ODN 2395 ( $\left.1 \mu \mathrm{m}\right)$. (d) Beas2B cells were treated with ODN $(1 \mu \mathrm{M})$. After the designated time, the supernatant was collected and the CCN1 level was measured using ELISA. (e) Beas2B cells were treated with ODN $(1 \mu \mathrm{m})$. After $4 \mathrm{~h}$, the supernatant was collected and ultracentrifuged to separate the exosomes and soluble factors. CCN1 was determined in both portions. (f) ODN was administered into C57/BL6 mice intranasally. BALF was collected after $24 \mathrm{~h}$. CCN1 was detected using ELISA. In all the Figures, ${ }^{\star} P<0.05$, compared with Sham. All Figures represented three independent experiments with identical results.

To test whether the above effects of ODN were triggered by the induction of CCN1 secretion, we administered anti-CCN1 antibodies in ODN/LPS-treated mice. ODN alone blocked the LPS-induced neutrophil accumulation in BAL. Neutralization of CCN1 abolished the effects of ODN, resulting in significantly higher neutrophil counts in both BAL and lung tissues (Figure 2e,f). Consistent with observations on neutrophil cell numbers and differentiations detected in BAL, neutralization of CCN1 notably reversed the inhibitory effects of ODN on LPS-induced TNF- $\alpha$ and MIP-2 levels in BALF (Figure 2g,h). We next confirmed this observation in vitro using alveolar macrophages. Neutralization of CCN1 using anti-CCN1 antibodies consistently reversed the effects of ODN on LPS-activated alveolar macrophages, as determined by both IL-6 and TNF- $\alpha$ levels (Supplementary Figure S2B). Furthermore, lung histological examination suggested that LPS-induced inflammation was reduced after ODN treatment. Anti-CCN1 antibodies reversed the anti-inflammatory effects of ODN (Figure 2i).

\section{CCN1 promoted IL-10 secretion via integrin $\alpha$ V $\beta 6$-mediated pathways}

To determine which cells secreted IL-10 after CCN1 treatment, we isolated primary mouse alveolar macrophages and epithelial cells. CCN1 and ODN both induced IL-10 production, either alone or synergistically with LPS in primary type II lung epithelial cells but not in alveolar macrophages (Figure 3a). In human A549 lung epithelial cells, CCN1 induced IL-10 secretion in a dose-dependent manner (Supplementary Figure S3A). Previous reports have suggested that integrin $\alpha \mathrm{V} \beta 6$ affects IL-10 secretion in other disease models. ${ }^{27}$ Therefore, we assessed the expression of integrin $\alpha \mathrm{V} \beta 6$ in lung epithelial cells after $\mathrm{CCN} 1$ stimulation. We found that $\mathrm{CCN} 1$ induced the expression of both integrin $\alpha \mathrm{V}$ and $\beta 6$ (Supplementary Figure S3B). Blocking integrin $\alpha \mathrm{V} \beta 6$ using neutralizing antibodies prevented CCN1-induced IL-10 release from primary mouse lung type II epithelial cells (Figure 3b). Furthermore, we confirmed that CCN1-induced IL-10 expression was downregulated after integrin $\alpha \mathrm{V} \beta 6$ neutralization in lung tissue using immunofluorescence (Figure 3c). To confirm the importance of integrin $\alpha \mathrm{V} \beta 6$ in mediating ODN/CCN1-induced IL-10 secretion, we administrated anti-integrin $\alpha \mathrm{V} \beta 6$ antibodies intranasally with either ODN or CCN1 into mice. Neutralization of integrin $\alpha \mathrm{V} \beta 6$ reversed the inhibitory effects of both ODN and CCN1 on LPS-induced neutrophil infiltration and TNF- $\alpha$ level in BALF (Figure 3d,e). We next evaluated the downstream signaling pathways of integrin $\alpha \mathrm{V} \beta 6$, which potentially 
a

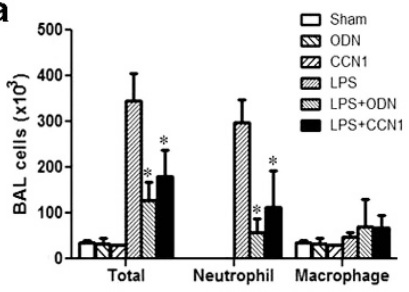

e

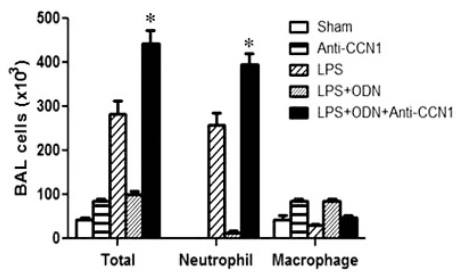

b

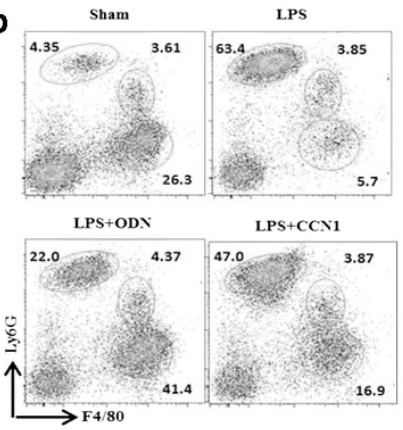

f

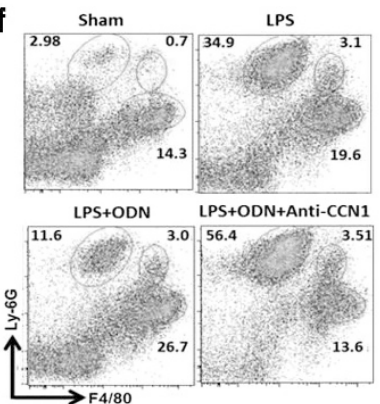

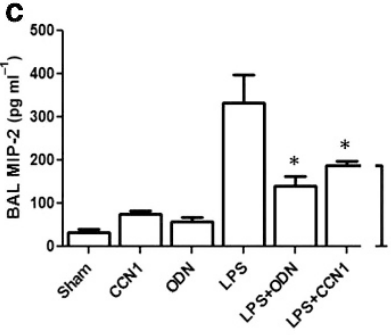

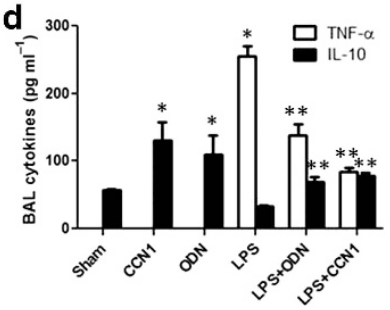

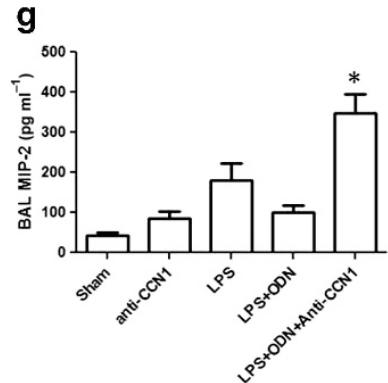

$\mathbf{h}$
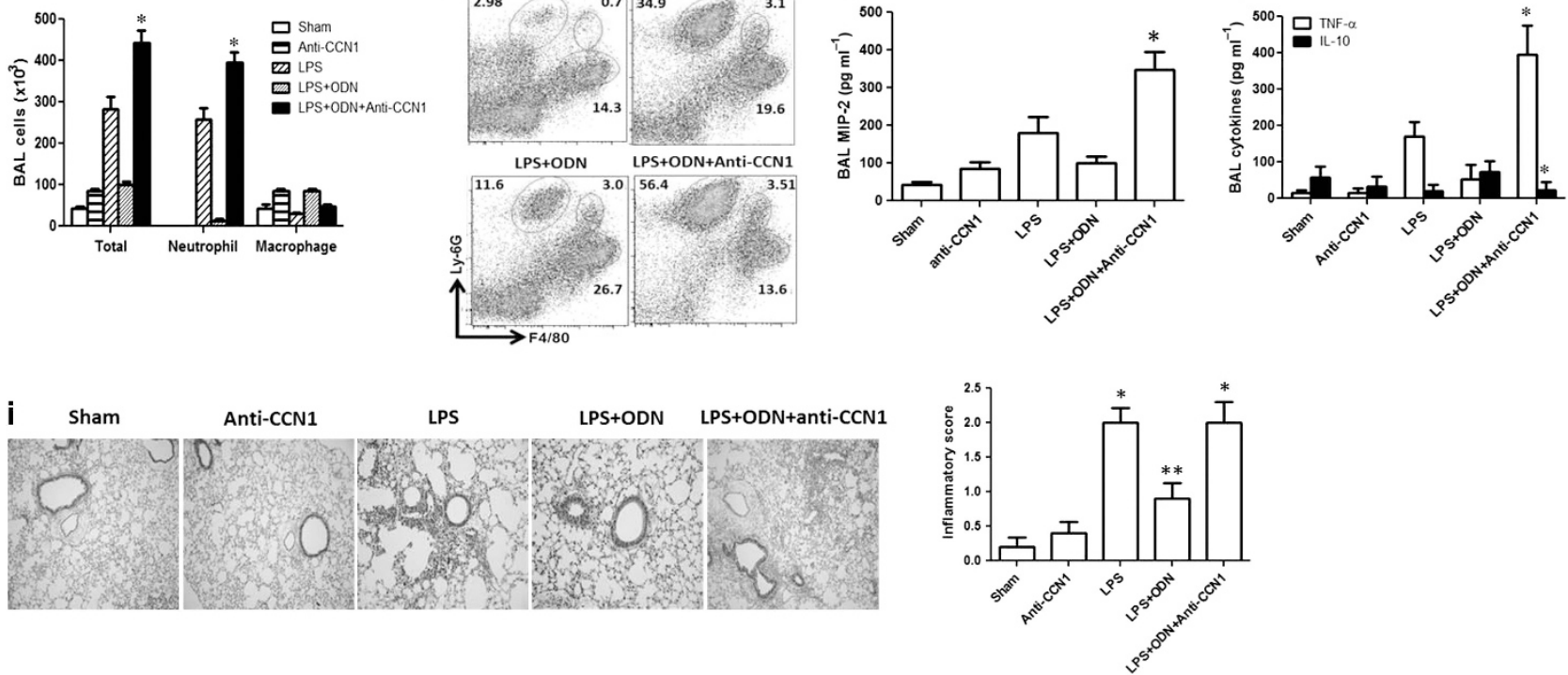

Figure 2 CpG oligonucleotide (ODN) induced CCN1 limits neutrophil infiltration in vivo. (a) CCN1 (5 $\mu \mathrm{g})$, ODN (10 $\mu \mathrm{g})$, and lipopolysaccharide (LPS $10 \mu \mathrm{g}$ ) was administered into C57/BL6 mice intranasally. After $24 \mathrm{~h}$, bronchoalveolar lavage fluid (BALF) was collected. Total cell counts and differentials were analyzed using Diff-Quick staining. ${ }^{*} P<0.05$, compared with LPS. (b) Pre-treatment of ODN/CCN1 at the same dose as the above resulted in less neutrophil infiltration in mouse lung tissue after LPS inhalation. Markers used for neutrophils: Ly6G + F4/80 - ; for alveolar macrophages: Ly6G-F4/80 + , and for interstitial macrophages: Ly6G + F4/80 + . (c) C57/BL6 mice were exposed to sham, CCN1, ODN, LPS, LPS + CCN1, or LPS + ODN at the same dose as in a. After $24 \mathrm{~h}$, macrophage inflammatory protein 2 (MIP-2) level in BALF was measured using enzyme-linked immunosorbent assay (ELISA). ${ }^{*} P<0.05$, compared with LPS treatment. (d) Tumor necrosis factor (TNF)- $\alpha$ and interleukin (IL)- 10 level in BALF were measured using ELISA. ${ }^{*} P<0.05$, compared with Sham, ${ }^{\star \star} P<0.05$ compared with LPS. (e) Anti-CCN1 $(5 \mu \mathrm{g})$, ODN (10 $\left.\mu \mathrm{g}\right)$, and LPS $(10 \mu \mathrm{g})$ were administered into C57/BL6 mice intranasally. After $24 \mathrm{~h}$, BALF was collected. Total cell counts and cell differentials were performed using Diff-Quick staining. ${ }^{*} P<0.05$, compared with LPS. (f) C57/BL6 mice were exposed to sham, LPS, ODN + LPS, or anti-CCN1 + ODN + LPS at the same dose as in e. After $24 \mathrm{~h}$, neutrophil infiltration in mouse lung tissue was analyzed using flow cytometer. Markers used for neutrophils: Ly6G + F4/80 - ; for alveolar macrophages: Ly6G-F4/80 + ; for interstitial macrophages: Ly6G + F4/80 + . (g) BAL MIP-2 level in same condition with e. After $24 \mathrm{~h}$, MIP-2 level in BALF was measured using ELISA. ${ }^{*} P<0.05$, compared with LPS + ODN. (h) TNF- $\alpha$ and IL-10 level in BALF were measured using ELISA. * $P<0.05$, compared with LPS + ODN. (i) Hematoxylin and eosin-stained lung tissue in the same condition with e (left panel). Lung inflammation was scored in 10 different spots per slide and five slides per group (right panel). ${ }^{*} P<0.05$, compared with Sham, ${ }^{* *} P<0.05$, compared with LPS. All Figures represented three independent experiments with identical results.

mediated the effects of CCN1 on IL-10 secretion. Inhibitors were used for various signaling pathways: Bay11-7082

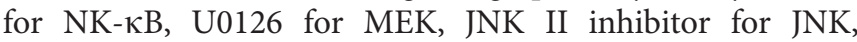
Y27632 for p160 ROCK, watmannin for PI3K, SB 203580 for p38 mitogen-activated protein kinase, and GO6850 for PKC. Cells were pre-treated with each inhibitor $(10 \mu \mathrm{M})$ $1 \mathrm{~h}$ before the treatment of CCN1 recombinant protein $\left(1 \mu \mathrm{g} \mathrm{ml}^{-1}\right)$. We found that only GO6850 (PKC inhibitor) blocked CCN1-induced IL-10 secretion (Figure 3f). Taken together, $\mathrm{CpG}$ ODN-induced CCN1 augmented IL-10 secretion via the integrin $\alpha \mathrm{V} \beta 6-\mathrm{PKC}$ pathway in lung epithelial cells.

\section{Cav-1 phosphorylation was crucial in regulating $\mathrm{CCN} 1$ secretion}

Our previous report suggests that Cav-1 is involved in the regulation of $\mathrm{CCN} 1$ secretion after oxidative stress. ${ }^{28}$ In this current study, we found that ODN promoted Cav-1 phosphorylation at Y14 in a time-dependent manner (Figure 4a). Next, we isolated primary type II lung epithelial cells from WT and $\mathrm{Cav}_{-1} 1^{-1-}$ mice and stimulated these cells with ODN. CCN1 secretion and expression in $\mathrm{Cav}^{-1} 1^{-1-}$ cells were remarkably reduced compared with similarly treated WT cells (Figure 4b). Pre-treatment of daidzein, a Cav-1 inhibitor, ${ }^{29}$ suppressed the ODN-stimulated CCN1 secretion 


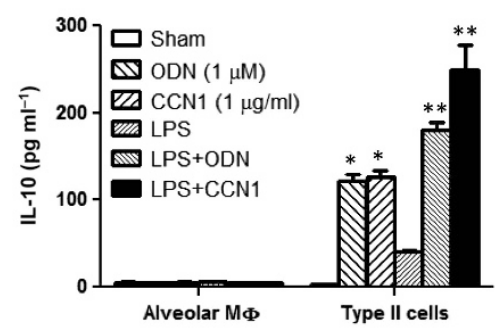

b

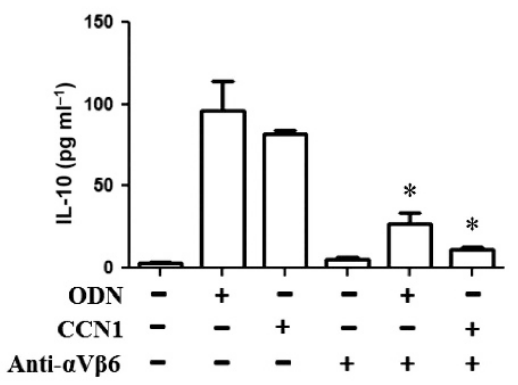

C

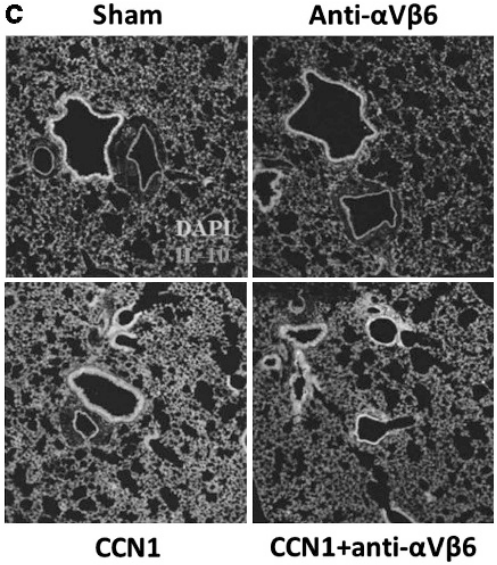

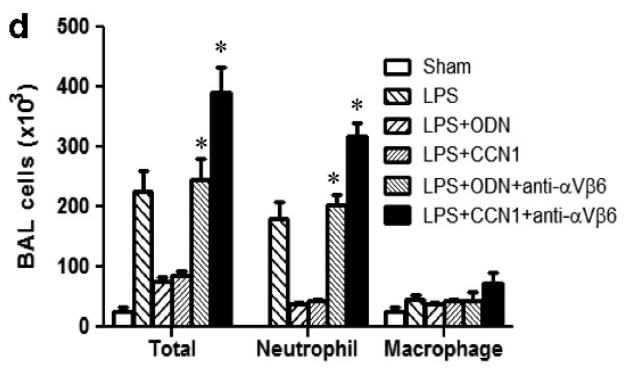
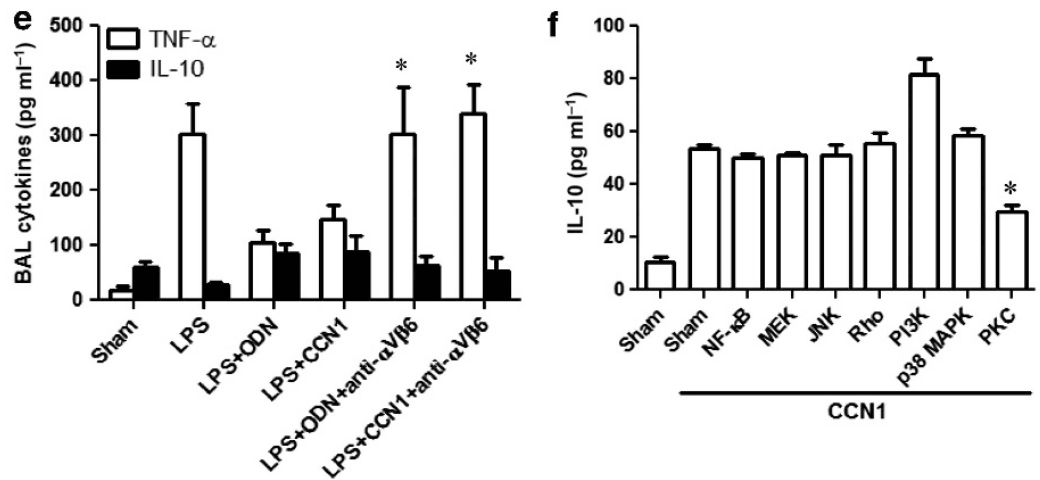

Figure 3 CCN1 promoted interleukin (IL)-10 secretion via integrin $\alpha$ V $\beta 6-P K C$ pathways in lung epithelial cells. (a) Primary alveolar macrophage and type II lung epithelial cells were treated with lipopolysaccharide (LPS; $100 \mathrm{ng} \mathrm{ml}^{-1}$ ), CCN1 $\left(1 \mu \mathrm{g} \mathrm{ml}^{-1}\right)$, and oligonucleotide (ODN) (1 $\left.\mu \mathrm{M}\right)$. IL-10 production after treatment was determined using enzyme-linked immunosorbent assay (ELISA). ${ }^{*} P<0.05$, compared with Sham, ${ }^{\star \star} P<0.05$, compared with LPS. (b) Inhibiting integrin $\alpha \mathrm{V} \beta 6$ using neutralizing antibodies $\left(5 \mu \mathrm{g} \mathrm{ml}^{-1}\right)$ prevented IL-10 production in primary type II lung epithelial cells. ${ }^{*} P<0.05$, compared with ODN and CCN1. (c) Neutralization of integrin $\alpha \mathrm{V} \beta 6$ reduced the CCN1-induced IL-10 expression in lung tissue. Recombinant CCN1 (5 $\mu \mathrm{g}$ ) with or without anti- $\alpha \mathrm{V} \beta 6$ antibody $(10 \mu \mathrm{g})$ was administered intranasally and samples were collected after $24 \mathrm{~h}$. (d) Anti- $\alpha \mathrm{V} \beta 6(10 \mu \mathrm{g}), \mathrm{ODN}(10 \mu \mathrm{g})$, CCN1 $(5 \mu \mathrm{g})$, and LPS $(10 \mu \mathrm{g})$ were administered into C57/BL6 mice intranasally. After $24 \mathrm{~h}$, bronchoalveolar lavage fluid (BALF) was collected. The cell counts and differentials were performed using Diff-Quick staining. ${ }^{*} P<0.05$, compared with ODN and CCN1. (e) Levels of tumor necrosis factor (TNF)- $\alpha$ and IL10 in BALF were measured using ELISA. ${ }^{*} P<0.05$, compared with ODN and CCN1. (f) Primary type II lung epithelial cells were pre-treated with each integrin signaling inhibitor and recombinant CCN1 $\left(1 \mu \mathrm{g} \mathrm{ml}^{-1}\right)$ was added. After $4 \mathrm{~h}$, IL-10 level was measured using ELISA. * $P<0.05$, compared with Sham. All Figures represented three independent experiments with identical results.

in a dose-dependent manner as well (Supplementary Figure S4A). Consistently, overexpression of Cav-1 in Beas2B cells augmented CCN1 secretion (Supplementary Figure S4B). Using co-immunoprecipitation assays, we demonstrated that CCN1 interacted with pCav-1 at a peak time between 15 and $45 \mathrm{~min}$. This interaction dissociated after $60 \mathrm{~min}$ (Figure 4c). The colocalization between CCN1 and pCav-1 was detected after ODN treatment (Figure 3d). CCN1 protein consists of five specific domains (SP, IGFbp, vWF, thrombospondin, and $\mathrm{CT}$ ) and each domain carries different protein-binding motifs. ${ }^{18}$ To determine the specific binding domain for pCav-1/CCN1 interactions, we generated specific domaindepleted $\mathrm{CCN} 1$ constructs and transfected them into Beas2B cells. For each construct, one specific domain was deleted. The interactions between $\mathrm{pCav}-1$ and CCN1 were diminished in the absence of domain 2 (IGFbp domain), suggesting that IGFbp is a crucial binding site of pCav-1 (Figure 4e). To confirm the effects of Cav-1 on CCN1 secretion in vivo, we administrated LPS with/without ODN intranasally into WT and Cav-1 ${ }^{-/-}$ mice. Deletion of Cav-1 reversed the ODN-suppressed neutrophil infiltration (Figure 4f) and reversed the effects of ODN of both TNF- $\alpha$ and IL-10 secretions (Figure 4g). These results indicated that $\mathrm{pCav}-1$ regulated $\mathrm{CCN} 1$ secretion and that pCav-1/IGFbp domain interaction was crucial in mediating CCN1 secretion.

\section{Cav-1 phosphorylation and CCN1 secretion were regulated by Src activation at Y527}

We have shown that pCav-1 was crucial to CCN1 secretion. Previous report shows that the phosphorylation of Cav-1 is triggered by Src tyrosine kinase. ${ }^{30}$ Therefore, we assessed the expression of Src, Src-Y416, and Src-Y527 in Beas2B cells after ODN stimulation. Expression levels of Src-Y416 and Src-Y527 were increased within $5 \mathrm{~min}$ after ODN treatment (Figure 5a). Deletion of Src reduced pCav-1 (Figure 5b) and CCN1 secretion (Figure 5c), suggesting that Src is important in the Cav-1-mediated CCN1 secretion. Next, to investigate whether the phosphorylation of Src is crucial in CCN1 secretion, we 
a

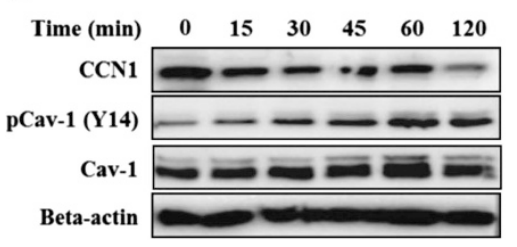

b

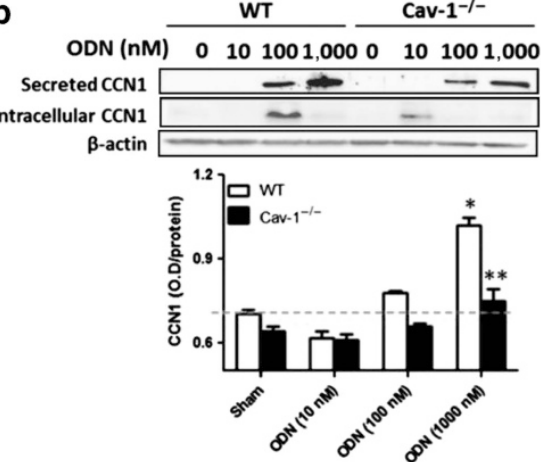

C

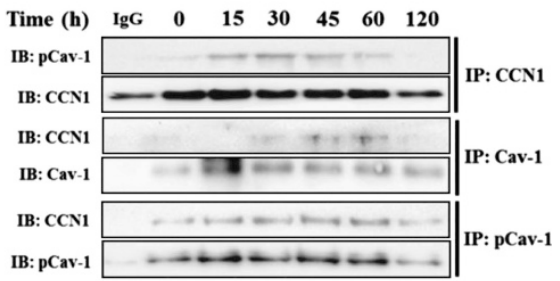

d

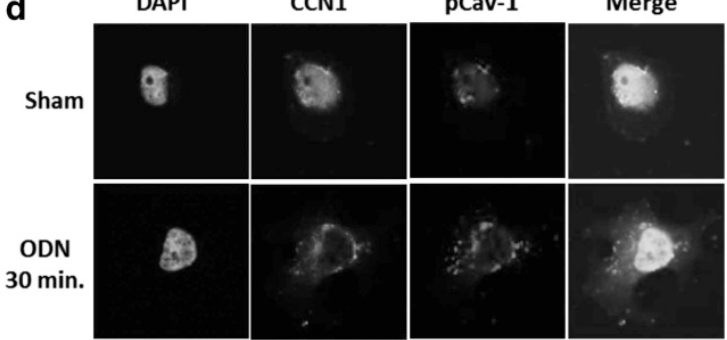

e
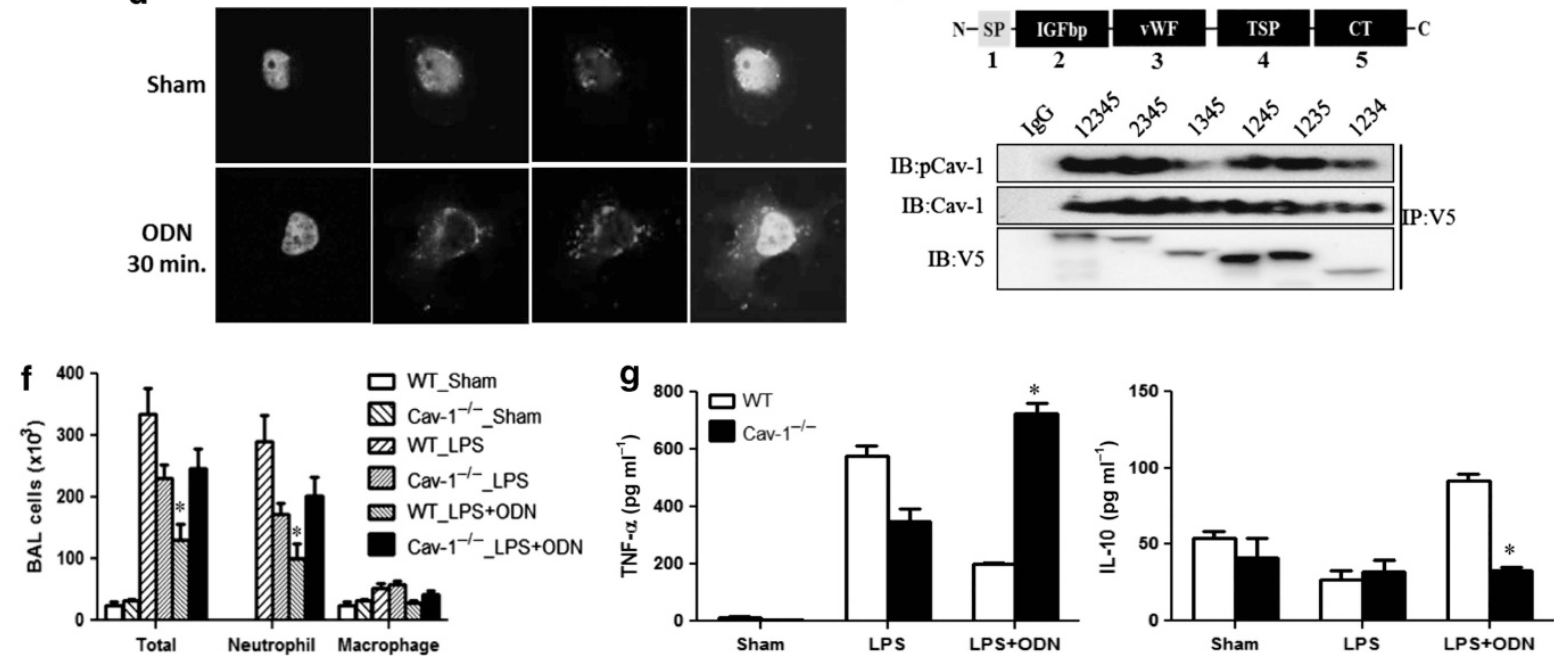

Figure 4 CCN1 secretion was regulated by Cav-1. (a) Beas2B cells were treated with oligonucleotide (ODN; $1 \mu \mathrm{m})$. After the designated time, CCN1 ( $\sim 42 \mathrm{kDa}$ ), Cav-1, pCav-1, and $\beta$-actin were detected using western blot analysis. (b) Primary type II lung epithelial cells were isolated from wild-type (WT) and Cav-1 ${ }^{-1}$ mice and treated with ODN for $4 \mathrm{~h}$. CCN1 was detected using western blot analysis (upper panel) and enzyme-linked immunosorbent assay (ELISA; lower panel). ${ }^{*} P<0.05$ compared to WT Sham, ${ }^{* *} P<0.05$ compared to WT ODN (1000 nM). (c) Beas2B cells were stimulated with ODN (1 $\mu \mathrm{M})$ in a time-dependent manner. Whole-cell lysate was incubated with anti-CCN1, anti-Cav-1, and anti-pCav-1 antibodies, respectively, followed by incubating with immunoglobulin $\mathrm{G}$ beads for $1 \mathrm{~h}$. Samples were then washed three times with RIPA buffer. Each precipitated protein was detected using western blot analysis. (d) Colocalization of CCN1 and pCav-1 after ODN (1 $\mu \mathrm{M})$ stimulation. CCN1 (fluorescein isothiocyanate (FITC)) and pCav-1 (Cy3) were detected using confocal microscopy. (e) Specific domain-depleted CCN1 constructs were transfected into Beas2B cells. After 2 days, cell lysate was subjected to western blot analysis using anti-V5, cav-1, and pCav-1 antibodies. (f) Lipopolysaccharide (LPS) \pm ODN was administered into the WT and Cav-1 ${ }^{-1}$ mice intranasally. Differential cell count was performed using the Diff-Quick staining. ${ }^{*} P<0.05$, compared with LPS. (g) Tumor necrosis factor (TNF)- $\alpha$ and interleukin (IL)-10 levels in bronchoalveolar lavage fluid (BALF) were measured using ELISA. ${ }^{*} P<0.05$, compared with LPS + ODN in WT. All Figures represented three independent experiments with identical results.

pre-treated Beas2B cells with Src phosphorylation inhibitor (PP2). PP2 suppressed Src phosphorylation at tyrosine 416 (Src-Y416) and 527 (Src-Y527), as well as Cav-1 phosphorylation (pCav-1; Figure 4d) and CCN1 secretion (Figure 5e). To determine the relevance of Src-Y527 and Y416 with Cav-1 phosphorylation and CCN1 secretion, we evaluated the expression of Src-Y416 and Y527 after silencing both CCN1 and Cav-1 using short interfering RNAs. Deletion of either CCN1 or Cav-1 diminished the expression of Src-Y527 but not Y416, suggesting that Y527 is important in the regulation of $\mathrm{CCN} 1$ and Cav-1 (Figure 4f). The interactions between pCav-1 and $\mathrm{Src}$ increased in a time-dependent manner (Figure 5g), whereas $\mathrm{CCN} 1 / \mathrm{Src}$ interactions peaked at $15 \mathrm{~min}$ after ODN stimulation (Figure 5g). Next, the domain-depleted CCN1 constructs were transfected into Beas2B cells. Deletion of domain 3 (vWF domain) resulted in significantly less interaction between $\mathrm{CCN} 1$ and $\mathrm{Src}$ or Src-Y527 (Figure 5h). To confirm our observations in vivo, we administered LPS with or without ODN to WT mice intranasally in the presence or absence of intraperitoneal PP2 treatment. ODN inhibited LPS-induced neutrophil infiltration in BALF; however, PP2 treatment reversed the effects of ODN (Figure 5i). PP2 also reversed the regulatory effects of ODN on TNF- $\alpha$ and IL-10, detected in BALF (Figure 5j). These results further supported the fact that Src phosphorylation, particularly Src-pY527, has a crucial role in Cav-1 phosphorylation and CCN1 secretion after ODN stimulation in lung epithelial cells.

ER stress-regulated CCN1 secretion induced by CpG ODN To further delineate the mechanisms by which CpG ODN regulated CCN1 secretion, we first determined the localization 
a

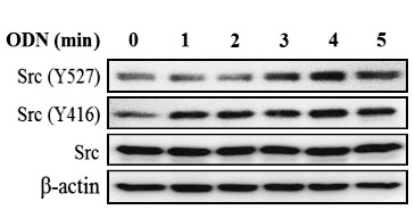

b

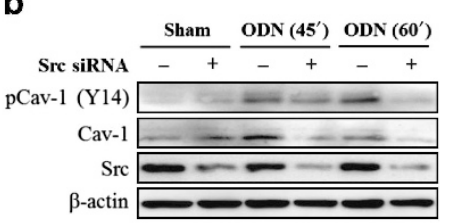

C

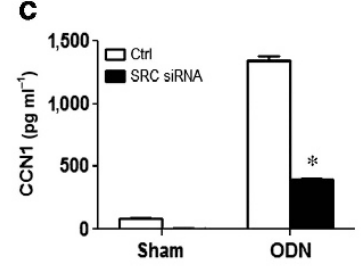

d

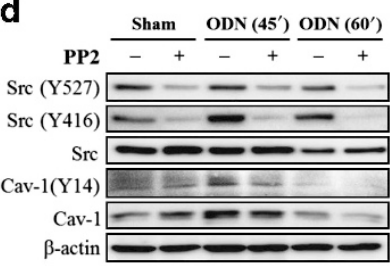

e

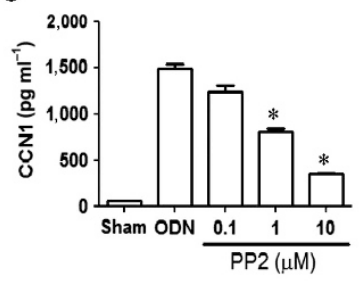

f

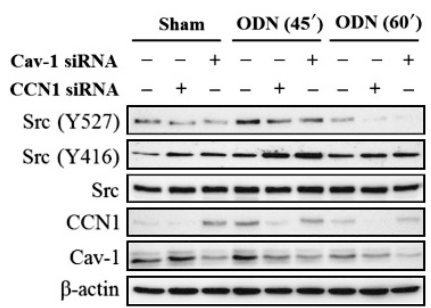

$\mathbf{9}$

h

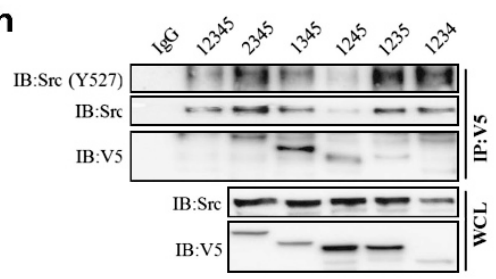

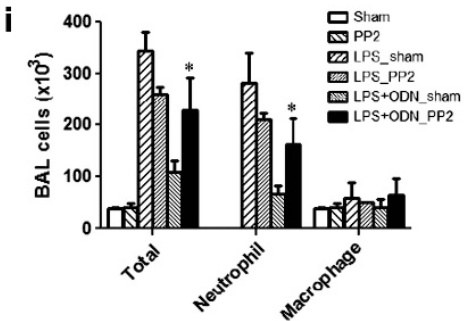

Figure 5 Cav-1 phosphorylation and CCN1 secretion were regulated by Src phosphorylation, particularly at Y527. (a) Beas2B cells were treated with oligonucleotide (ODN) (1 $\mu \mathrm{m})$. Src, Src-Y416, and Src-Y527 were detected. (b) Beas2B cells were transfected with Src short interfering RNA (siRNA). After 2 days, cells were treated with ODN $(1 \mu \mathrm{m})$ for 45 and $60 \mathrm{~min}$. $\beta$-actin, Cav-1, pCav-1, and Src were detected using western blot analysis. (c) After Src silencing using siRNAs, Beas2B cells were treated with ODN $(1 \mu \mathrm{m})$ for $4 \mathrm{~h}$. CCN1 was measured using enzyme-linked immunosorbent assay (ELISA). (d) Beas2B cells were pre-treated with PP2, inhibitor of Src phosphorylation. After 45 or 60 min, $\beta$-actin, Cav-1, pCav-1, Src, Src-Y416, and Src-Y527 were detected. (e) Beas2B cells were pre-treated with PP2, for $1 \mathrm{~h}$, and ODN for $4 \mathrm{~h}$. CCN1 was measured using ELISA. (f) Co-immunoprecipitation (Co-IP) assays between Src or CCN1 and pCav-1 in Beas2B cells were performed after ODN stimulation in a time-dependent manner. (g) Specific domaindepleted CCN1 constructs (with V5 tag) were transfected into Beas2B cells. After 2 days, V5 and Src were detected using western blot analysis. (h) Beas2B cells were transfected with CCN1 or Cav-1 siRNAs. After 2 days, ODN ( $1 \mu \mathrm{m})$ was added. Forty-five and sixty minutes after adding ODN, $\beta$-actin, Cav-1, CCN1, Src, Src-Y416, and Src-Y527 were detected. (i) Lipopolysaccharide (LPS) with or without ODN (1 $\mu \mathrm{m})$ was administered into C57/BL6 mice intranasally. PP2 $\left(5 \mathrm{mg} \mathrm{kg}^{-1}\right)$ was administrated intraperitoneally. After $24 \mathrm{~h}, \mathrm{BALF}$ was collected. Cell counts were assessed. ${ }^{\star} P<0.05$, compared with LPS + ODN_Sham. (j) Tumor necrosis factor (TNF)- $\alpha$ and interleukin (IL)-10 levels in BALF were measured using ELISA. ${ }^{*} P<0.05$, compared with LPS + ODN_Sham. All Figures represented three independent experiments with identical results.

of $\mathrm{CpG}$ ODN in major cell organelles. We found that $\mathrm{CpG}$ ODN-fluorescein isothiocyanate colocalized with the endoplasmic reticulum (ER)-associated protein $\mathrm{BiP} / \mathrm{GRP78}$ as observed using confocal microscopy (Figure 6a). We next evaluated the effects of ODN on the expression of ER stressassociated proteins, including BiP/GRP78 and CCAATenhancer-binding protein homologous protein (CHOP). Expression of $\mathrm{BiP} / \mathrm{GRP} 78$ or $\mathrm{CHOP}$ was increased at 1 or 3 min, respectively, after ODN stimulation (Figure 6b). To investigate the association of ER stress signaling with the CCN1 secretion, we treated the Beas $2 \mathrm{~B}$ cells with chemical inhibitors of various ER stress pathways. JNK (JNK inhibitor), mitogen-

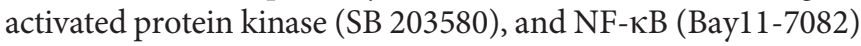
inhibitors were used for Ire-1-associated pathways; perk inhibitor was used for perk pathway; and $\gamma$-secretase inhibitor for the ATF6 cleavage pathway. Blocking the JNK pathway significantly reduced the CCN1 secretion (Figure 6c). Deletion of ER stress protein BiP or JNK using short interfering RNAs significantly suppressed the ODN-induced CCN1 secretion in Beas2B cells (Figure 6d). Furthermore, deletion of ER stress-associated protein BiP inhibited expression of $\mathrm{pSrc}$ Y527, pSrc-Y416 (Figure 6e), Cav-1, and pCav-1(Y14) (Figure 6f). However, $\mathrm{BiP}$ expression was independent to Src and its phosphorylation (Supplementary Figure S5A,B). Inhibition of JNK diminished the level of pCav-1 (Figure 6f, Supplementary Figure S5D). JNK activation (pJNK) was regulated by Src phosphorylation (Supplementary Figure S5E) but independent of Cav-1 (Supplementary Figure S5F). Dissociation of CCN1/Src was an important step for ODNtriggered CCN1 secretion, as presented in above data (Figure 5). The dissociation of CCN1/Src interaction after ODN stimulation was suppressed by $\mathrm{BiP}$ depletion (Figure 6g), suggesting the involvement of ER stress in this process. Taken together, ER stress is the initiator of ODN-induced CCN1 secretion, followed by Src-Y527 and Cav-1 phosphorylation (Supplementary Figure S6A, B), in lung epithelial cells.

\section{DISCUSSION}

Lung epithelial cells are constantly exposed to environmental toxicants and pathogens. Bacterial infections trigger the acute 
a

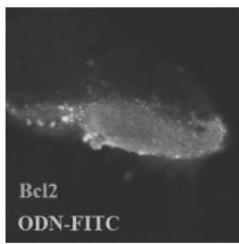

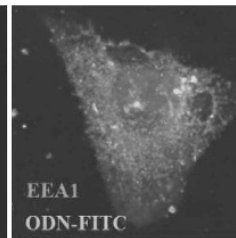
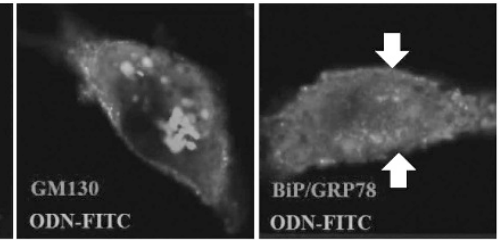

b

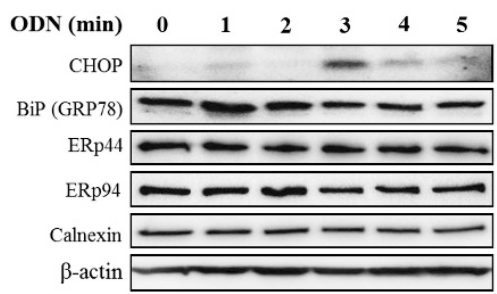

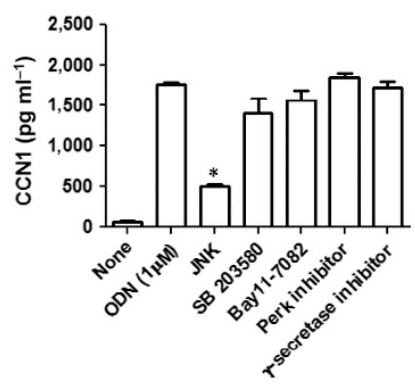

d

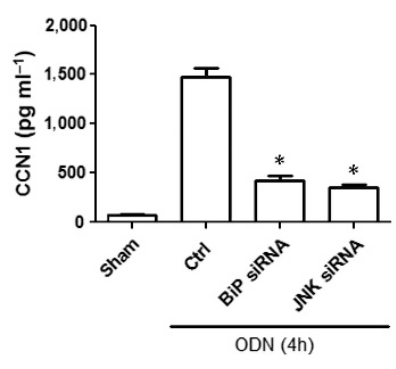

e

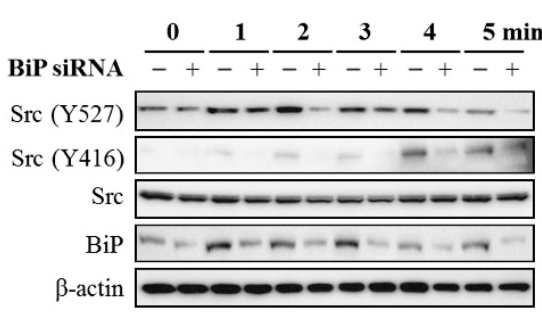

f

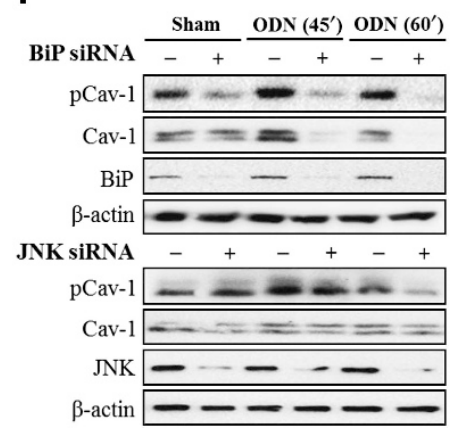

g

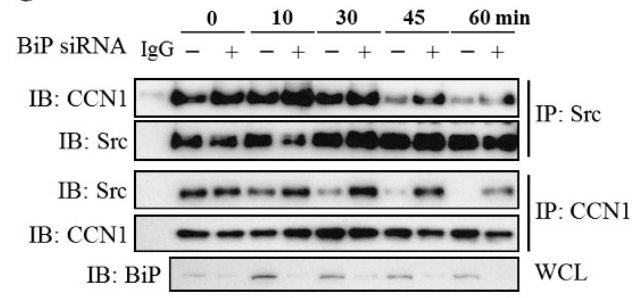

Figure 6 CpG oligonucleotide (ODN) localized in endoplasmic reticulum (ER) and triggered ER stress. (a) Beas2b cells were treated with CpG ODNfluorescein isothiocyanate (FITC) $(1 \mu \mathrm{M})$. The localization of CpG ODN was observed using confocal microscope. Markers for the mitochondria, Bcl2; for endosome, early endosome antigen 1 (EEA1); for the lysosome, LAMP-1; for Golgi, GM130; for ER, BiP/GRP78. (b) Beas2B cells were treated with ODN $(1 \mu \mathrm{m})$. Within $5 \mathrm{~min}$, calnexin, ERp94, ERp44, BiP, CHOP (CCAAT-enhancer-binding protein homologous protein), and $\beta$-actin were evaluated using western blot analysis. (c) Beas2B cells were exposed to each inhibitor. After $1 \mathrm{~h}$, cells were exposed to ODN (1 $\mu \mathrm{m})$. After additional $4 \mathrm{~h}$, CCN1 was measured using enzyme-linked immunosorbent assay (ELISA). Inhibitors used for JNK, JNK inhibitor; for mitogen-activated protein kinase (MAPK), SB 203580; for NF-KB (nuclear factor kappa-light-chain-enhancer of activated B cells), Bay 11-7082; for Perk, Perk inhibitor; for ATF6 activation, $\gamma$-secretase inhibitor. (d) Beas2B cells were transfected with BiP or JNK short interfering RNAs (siRNAs). After 2 days, cells were then treated with ODN (1 $\mu \mathrm{M})$. After additional $4 \mathrm{~h}, \mathrm{CCN} 1$ was measured using ELISA. (e) Beas2B cells were transfected with BiP siRNA. After 2 days, BiP, Src, Src (Y416), and Src (Y527) were detected using western blot analysis. (f) Beas2B cells were transfected with BiP or JNK siRNAs, followed by treatment of ODN as the above. BiP, JNK, Cav-1, pCav-1, and $\beta$-actin were detected. (g) Beas2B cells were transfected with BiP siRNA. After 2 days, whole-cell lysate was incubated with antiCCN1 or anti-Src, respectively. Cells were then incubated with IgG beads for $1 \mathrm{~h}$ and washed out three times with RIPA buffer. Each precipitated sample was detected using western blot analysis. All Figures represented three independent experiments with identical results.

inflammatory responses that are bactericidal but potentially carry consequences of tissue damage leading to lung injury. ${ }^{3}$ To maintain the integrity of the lung epithelium and ensure effective physiological functions, lung epithelial cells are armed with 'self-limiting' systems to control 'runaway' inflammatory responses. Here, we identified a novel paradigm in which the homeostasis of innate immunity and inflammation are regulated by lung epithelial cells.

We showed that the CCN1 secretion from lung epithelial cells was robustly enhanced by CpG ODN/bacterial DNAs in a TLR9-independent manner. Currently, the potential receptors/ pathways by which $\mathrm{CpG}$ ODN induces $\mathrm{CCN} 1$ secretion remain unclear and under further investigation. CCN1 gene expression and secretion are augmented by mechanical stretch, oxidative stress, growth factors, and cytokines through diverse signaling pathways. ${ }^{18}$ To eradicate the bacteria, innate immune cells generate proteolytic enzymes, radical oxygen and granules, whereas epithelial cells secrete $\beta$-defensin. ${ }^{31-33}$ During this bactericidal process, we suspect that bacterial DNA was leaked to extracellular matrix from the damaged bacteria. At this point, the leaked bacterial DNAs in extracellular matrix were recognized by the surrounding lung epithelial cells and triggered a signaling cascade to secrete CCN1. We will further investigate the cell type-specific bacterial clearance and bacterial DNA leakage in vitro and in vivo. This bacterial DNA-induced CCN1 exerted anti-inflammatory effects in a paracine/autocrine manner, including promoting IL-10 release, suppressing both MIP-2 and TNF- $\alpha$ levels. Consequently, neutrophil infiltration, but not macrophage and dendritic cell infiltrations, was inhibited in lung parenchyma (Not shown). 
Thus, CCN1 potentially functioned as a "braking" molecule to bacterial infection-associated lung inflammatory responses.

ER stress often refers to both ER dysfunction and loss of its homeostasis in the presence of stressful stimuli, such as bacterial infection. ${ }^{34}$ The effects of pathogens on ER stress robustly affect the innate and adaptive immune responses. Previous studies have demonstrated that bacterial infection, particularly Gram-negative bacteria-derived LPS, induces lung inflammation via triggering ER stress. ${ }^{35}$ Particularly, the $\mathrm{CHOP}$-associated ER stress has been shown to participate in the pathogenesis of sepsis-associated inflammation, cell death, and lung injury. ${ }^{35,36}$ However, how the host responds to pathogen-induced ER stress remains largely unclear. Interestingly, the ER stress-associated proteins ( $\mathrm{BiP}, \mathrm{CHOP}$ ), besides being involved in the inflammatory responses, also facilitated the secretion of $\mathrm{CCN} 1$ to the matrix. In the presence of inflammatory inducers, such as bacterial DNAs and CpG ODN motifs, CCN1 exerts anti-inflammatory features, shown in our current studies. However, ER stress in lung epithelial cells can also be induced by a variety of non-infectious stimuli, such as cigarette smoke and hyperoxia. ${ }^{20,37}$ These environmental stimuli, such as cigarette smoke, are less likely to induce the similar inflammatory process after bacterial infection. In fact, we have shown that the cigarette smokeinduced CCN1 acts as a pro-inflammatory, rather than antiinflammatory agent. ${ }^{20}$ In another example, CCN1 has been reported previously to promote inflammation and wound repair. ${ }^{38-40}$ In these studies, Bai et al. ${ }^{38}$ demonstrated that a high dose of CCN1 $\left(10 \mu \mathrm{g} \mathrm{ml}^{-1}\right)$ treatment leads to an upregulation of pro-inflammatory cytokine/chemokine mRNAs in macrophages. CCN1 supports the adhesion of macrophages, activates NF- $\mathrm{KB}$-mediated transcription, and induces pro-inflammatory cytokines that are generated by classically activated M1 macrophages. ${ }^{38}$ It is not surprising to us that $\mathrm{CCN} 1$ has a dual role in response to the inflammation triggered by different stimuli. Besides inflammation, numerous reports have also demonstrated that CCN1 carries dual roles in cell death. CCN1 has been shown to confer cytoprotection in many cell types including, but not limited to, lung epithelial cells, endothelial cells, intestinal epithelial cells, and cardiomyocytes. ${ }^{18,19,41,42}$ On the other hand, CCN1 has also been reported to induce apoptosis in fibroblasts. ${ }^{43}$ One of the main explanations for the differential functions of CCN1 in cell death is associated with surface integrins that $\mathrm{CCN} 1$ binds to. For instance, $\mathrm{CCN} 1$ exerts its cytoprotective effects via integrin $\alpha \mathrm{V} \beta 3$ while causing cell death via integrin $\alpha 6 \beta 1{ }^{41,43}$ Therefore, we hypothesized that CCN1 carries either pro-inflammatory or anti-inflammatory effects depending on the different cell surface integrins. In fact, in our current studies, CCN1 exerted its anti-inflammatory functions via integrin $\alpha \mathrm{V} \beta 6$, but not integrin $\alpha \mathrm{V} \beta 2$, which is known to mediate pro-inflammatory effects of CCN $1 .{ }^{38}$ Taken together, to maintain the homeostasis of lung microenvironment, it is very possible that CCN1 functions as an anti-inflammatory factor in response to acute infection phase. The timing, route, and amount of CCN1 secretion triggered by the "sterile" ER stress can be significantly different compared with when it is infectious pathogentriggered. The dual function of $\mathrm{CCN} 1$ may well be regulated according to multiple factors, including the stimuli, the cell type, the lung microenvironment, and the amount of secretion. The detailed functions of $\mathrm{CCN} 1$, in response to each specific stimulus, require further exploration.

CCN1 promoted IL-10 release via the integrin $\alpha \mathrm{V} \beta 6-\mathrm{PKC}$ pathway. In the promoter region of IL-10, there are multiple transcriptional factor-binding sites that can be activated by CCN1. For instance, the NF- $\mathrm{KB} .{ }^{44} \mathrm{CCN} 1$ has been reported to exert its functions via both an immediate-early response resulting from direct activation of $\mathrm{NF}-\mathrm{\kappa B}$ and a delayed response resulting from CCN1-induced cytokines. ${ }^{38}$ Furthermore, the expression of integrin $\alpha \mathrm{V} \beta 6$ is rapidly increased in epithelial cells upon inflammation and involved in immune suppression. ${ }^{45}$ Importantly, previous studies demonstrate that the function of $\alpha \mathrm{V} \beta 6$ is through the activation of transforming growth factor $\beta$ by binding the latency-associated peptide. ${ }^{46}$ transforming growth factor $\beta$ is known to drive the production of IL-10. ${ }^{47}$ Thrombospondin-1 has been known as one of the major activators of TGF- $\beta .^{48}$ More interestingly, there is a thrombospondin-1-like domain (domain 3, Figure 4e) existing in the full-length CCN1. ${ }^{18}$ Therefore, it is possible that CCN1 also induces IL-10 via a latent/indirect pathway via thrombospondin-1 domain-activated transforming growth factor $\beta$. Furthermore, the production of IL-10 is regulated by PKC $\delta$ signaling after LPS stimulation in bone marrowderived macrophage. ${ }^{49}$ IL-10 is one of the major mediators involved in the host defense against the infection-induced inflammation. ${ }^{12,14}$ Consistently, our studies showed that CCN1-induced IL-10 contributed to preserve lung homeostasis by suppressing TNF- $\alpha$, MIP-2 level, and neutrophil counts in BALF (Figure 2). However, lung epithelial cell probably is not the only cell type that secretes IL-10 after CpG ODN stimulation. Other immune cells (for example, plasmacytoid dendritic cells) may also generate IL-10 in this circumstance. One of the limitations in this study is that we did not address IL-10 secretion from other cells.

Our studies focused on the lung epithelial cell-derived CCN1s induced by bacterial DNA or synthetic bacterial DNA motif in the form of CpG ODNs. One future direction will be to explore the direct interactions between $\mathrm{CCN} 1$ and bacteria, as well as the functions of CCN1 in bacterial adherence, invasion, and proliferation. Moreover, we will investigate the virustriggered CCN1 secretion and its function. We observed influenza- and RSV-infection-stimulated CCN1 secretion in in vivo infection model (not shown). Whether the virustriggered $\mathrm{CCN} 1$ is pro- or anti-inflammatory remains unclear. The coexistence of both bacterial and viral infections is a common scenario seen in upper airway infections, pneumonia, and pneumonitis. Exploration of the role of CCN1 in this complicated process potentially opens a novel area for lung infection research.

In summary, our studies demonstrated a novel paradigm by which hosts maintain the fine balance between the innate 
immunity/bactericidal effects and the "runaway" inflammation that can cause lung injury. Bacterial DNA/CpG motif triggered CCN1 secretion via ER stess-Src-JNK-Cav-1 pathways. These lung epithelial cell-derived CCN1s exerted anti-inflammatory functions via promoting IL-10 and inhibiting multiple proinflammatory cytokines, as well as the neutrophil infiltrations in the lung.

\section{METHODS}

Mouse. Age (See Supplementary Information) and sex-matched 6- to 8-week-old C57BL/6 and Cav-1-deficient mice were purchased from Jackson Laboratory (Bar Harbor, ME) and housed under pathogenfree conditions at the animal facility at Brigham and Women's Hospital. All animal experiment protocols were approved by the Harvard Standing Committee for Animal Welfare.

Cell culture. A549, Beas2B, and HBE cells were obtained from ATCC (Manassas, VA). Beas2B and A549 cells were cultured in DMEM medium with $10 \%$ fetal bovine serum (GIBCO, Grand Island, NY). HBE cells were cultured in primary epithelial cell basal media with supplement (ATCC). All cells were grown at $37{ }^{\circ} \mathrm{C}$ in a humidified atmosphere of $5 \% \mathrm{CO}_{2}$. Primary type II lung epithelial cells were isolated by following previous descriptions. ${ }^{50}$

SUPPLEMENTARY MATERIAL is linked to the online version of the paper at http://www.nature.com/mi

\section{ACKNOWLEDGMENTS}

This work is supported by the National Institutes of Health R01 HL102076 (Y.J.) and the National Natural Science Foundation of China 81370103 (L.X.). We thank Dr Augustine M.K. Choi and Dr Lester F. Lau for their scientific discussions and support. We also thank Mr Jincheng Yang for his help on editing the manuscript.

\section{DISCLOSURE}

The authors declare no conflict of interests.

(c) 2015 Society for Mucosal Immunology

\section{REFERENCES}

1. Eddens, T \& Kolls, J.K. Host defenses against bacterial lower respiratory tract infection. Curr. Opin. Immunol. 24, 424-430 (2012).

2. Tam, A, Wadsworth, S, Dorscheid, D, Man, S.F. \& Sin, D.D. The airway epithelium: more than just a structural barrier. Ther. Adv. Respir. Dis. 5, 255-273 (2011)

3. Grainge, C.L. \& Davies, D.E. Epithelial injury and repair in airways diseases. Chest 144, 1906-1912 (2013).

4. Bauer, S. et al. Human TLR9 confers responsiveness to bacterial DNA via species-specific CpG motif recognition. Proc. Natl Acad. Sci. USA 98, 9237-9242 (2001).

5. Dalpke, A, Zimmermann, S \& Heeg, K. CpG DNA in the prevention and treatment of infections. BioDrugs 16, 419-431 (2002).

6. Wooldridge, J.E., Ballas, Z, Krieg, A.M. \& Weiner, G.J. Immunostimulatory oligodeoxynucleotides containing $\mathrm{CpG}$ motifs enhance the efficacy of monoclonal antibody therapy of lymphoma. Blood 89, 2994-2998 (1997).

7. Krug, A. et al. Identification of $\mathrm{CpG}$ oligonucleotide sequences with high induction of IFNalpha/beta in plasmacytoid dendritic cells. Eur. J. Immunol. 31, 2154-2163 (2001).

8. Cardon, L.R., Burge, C, Clayton, D.A. \& Karlin, S. Pervasive CpG suppression in animal mitochondrial genomes. Proc. Natl Acad. Sci. USA 91, 3799-3803 (1994).

9. Moore, T.A. \& Standiford, T.J. Cytokine immunotherapy during bacterial pneumonia: from benchtop to bedside. Semin. Respir. Infect. 16, 27-37 (2001).
10. Cazzola, M, Matera, M.G. \& Pezzuto, G. Inflammation-a new therapeutic target in pneumonia. Respiration 72, 117-126 (2005).

11. Levy, B.D. \& Serhan, C.N. Resolution of acute inflammation in the lung. Annu. Rev. Physiol. 76, 467-492 (2014).

12. Steinhauser, M.L., Hogaboam, C.M., Kunkel, S.L., Lukacs, N.W., Strieter, R.M. \& Standiford, T.J. IL-10 is a major mediator of sepsis-induced impairment in lung antibacterial host defense. J. Immunol. 162, 392-399 (1999).

13. Ouyang, W, Rutz, S, Crellin, N.K., Valdez, P.A. \& Hymowitz, S.G. Regulation and functions of the IL-10 family of cytokines in inflammation and disease. Annu. Rev. Immunol. 29, 71-109 (2011).

14. Qureshi, M.H., Harmsen, A.G. \& Garvy, B.A. IL-10 modulates host responses and lung damage induced by Pneumocystis carinii infection. J. Immunol. 170, 1002-1009 (2003).

15. Muenzer, J.T. et al. Characterization and modulation of the immunosuppressive phase of sepsis. Infect. Immun. 78, 1582-1592 (2010).

16. Sun, L. et al. Dual role of interleukin-10 in the regulation of respiratory syncitial virus (RSV)-induced lung inflammation. Clin. Exp. Immunol. 172, 263-279 (2013).

17. Schütze, N, Rücker, N, Müller, J, Adamski, J \& Jakob, F. 5' flanking sequence of the human immediate early responsive gene ccn1 (cyr61) and mapping of polymorphic CA repeat sequence motifs in the human ccn1 (cyr61) locus. Mol. Pathol. 54, 170-175 (2001).

18. Jun, J.I. \& Lau, L.F. Taking aim at the extracellular matrix: CCN proteins as emerging therapeutic targets. Nat. Rev. Drug Discov. 10, 945-963 (2011).

19. Jin, Y, Kim, H.P., Ifedigbo, E, Lau, L.F. \& Choi, A.M. Cyr61 protects against hyperoxia-induced cell death via Akt pathway in pulmonary epithelial cells. Am. J. Respir. Cell Mol. Biol. 33, 297-302 (2005).

20. Moon, H.G., Zheng, Y, An, C.H., Kim, Y.K. \& Jin, Y. CCN1 secretion induced by cigarette smoking extracts augments IL-8 release from bronchial epithelial cells. PLOS ONE 8, e68199 (2013).

21. Mo, F.E., Muntean, A.G., Chen, C.C., Stolz, D.B., Watkins, S.C. \& Lau, L.F. CYR61 (CCN1) is essential for placental development and vascular integrity. Mol. Cell Biol. 22, 8709-8720 (2002).

22. Leeper-Woodford, S.K. et al. Tumor necrosis factor. alpha and beta subtypes appear in circulation during onset of sepsis-induced lung injury. Am. Rev. Respir. Dis. 145, 1076-1082 (1991).

23. Krieg, A. CpG motifs in bacterial DNA and their immune effects. Annu. Rev. Immunol. 20, 709-760 (2002)

24. Krieg, A. Therapeutic potential of Toll-like receptor 9 activation. Nat. Rev. Drug Discov. 5, 471-484 (2006).

25. Sheridan, B.C., Mclntyre, R.C., Meldrum, D.R. \& Fullerton, D.A. Pentoxifylline treatment attenuates pulmonary vasomotor dysfunction in acute lung injury. J. Surg. Res. 71, 150-154 (1997).

26. Mosser, D.M. \& Zhang, X. Interleukin-10: new perspectives on an old cytokine. Immunol. Rev. 226, 208-218 (2008).

27. Sugimoto, K. et al. The $a \vee \beta 6$ integrin modulates airway hyperresponsiveness in mice by regulating intraepithelial mast cells. J. Clin. Invest. 122, 748-758 (2012).

28. Jin, Y, Kim, H.P., Cao, J, Zhang, M, Ifedigbo, E \& Choi, A.M. Caveolin-1 regulates the secretion and cytoprotection of Cyr61 in hyperoxic cell death. FASEB J. 23, 341-350 (2009).

29. Woodman, O.L., Missen, M.A. \& Boujaoude, M. Daidzein and 17 beta-estradiol enhance nitric oxide synthase activity associated with an increase in calmodulin and a decrease in caveolin-1. J. Cadiovasc. Pharmacol. 44, 155-163 (2004).

30. Li, S, Seitz, R \& Lisanti, M.P. The alpha-isoform of caveolin is selectively phosphorylated by v-Src in vivo. J. Biol. Chem. 274, 3863-3868 (1996).

31. Segal, A.W. How neutrophils kill microbes. Annu. Rev. Immunol. 23, 197-223 (2005).

32. Baxt, L.A., Garza-Mayers, A.C. \& Goldberg, M.B. Bacterial subversion of host innate immune pathways. Science 340, 697-701 (2013).

33. Singh, P.K. et al. Production of beta-defensins by human airway epithelia. Proc. Natl Acad. Sci. USA 95, 14961-14966 (1998).

34. Martinon, F. The endoplasmic reticulum: a sensor of cellular stress that modulates immune responses. Microbes Infect. 14, 1293-1300 (2012).

35. Kim, H.J., Jeong, J.S., Kim, S.R., Park, S.Y., Chae, H.J. \& Lee, Y.C. Inhibition of endoplasmic reticulum stress alleviates lipopolysaccharide-induced lung 
inflammation through modulation of NF-kB/HIF- $1 \alpha$ signaling pathway. Sci. Rep. 3, 1142 (2013).

36. Endo, M, Oyadomari, S, Suga, M, Mori, M \& Gotoh, T. The ER stress pathway involving CHOP is activated in the lungs of LPS-treated mice. J. Biochem. 138, 501-507 (2005).

37. Gewandter, J.S., Staversky, R.J. \& O'Reilly, M.A. Hyperoxia augments ERstress-induced cell death independent of BiP loss. Free Radic. Biol. Med. 47, 1742-1752 (2009).

38. Bai, T, Chen, C.C. \& Lau, L.F. Matricellular protein CCN1 activates a proinflammatory genetic program in murine macrophages. J. Immunol. 184, 3223-3232 (2010).

39. Jun, J.I. \& Lau, L.F. The matricellular protein CCN1 induces fibroblast senescence and restricts fibrosis in cutaneous wound healing. Nat. Cell Biol. 12, 676-685 (2010).

40. Minhas, U, Martin, T.A., Ruge, F, Harding, K.G. \& Jiang, W.G. Pattern of expression of CCN family members Cyr61, CTGF and NOV in human acute and chronic wounds. Exp. Ther. Med. 2, 641-645 (2011).

41. Hsu, P.L., Su, B.C., Kuok, Q.Y. \& Mo, F.E. Extracellular matrix protein CCN1 regulates cardiomyocyte apoptosis in mice with stress-induced cardiac injury. Cardiovasc. Res. 98, 64-72 (2013).

42. Koon, H.W. et al. Substance P-mediated expression of the pro-angiogenic factor CCN1 modulates the course of colitis. Am. J. Pathol. 173, 400-410 (2008).
43. Todorovic, V, Chen, C.C., Hay, N \& Lau, L.F. The matrix protein CCN1 (CYR61) induces apoptosis in fibroblasts. J. Cell Biol. 171, 559-568 (2005).

44. Saraiva, M \& O'Garra, A. The regulation of IL-10 production by immune cells. Nat. Rev. Immunol. 10, 170-181 (2010).

45. Wu, X.M., Liao, Y.W., Wang, H.Y., Ji, K.Q., Li, G.F. \& Zang, B. Integrin alphavbeta6 is involved in measles protein-induced airway immune suppression. Cytokine 59, 59-64 (2012).

46. Munger, J.S. et al. The integrin alpha $v$ beta 6 binds and activates latent TGF beta 1: a mechanism for regulating pulmonary inflammation and fibrosis. Cell 96, 319-328 (1999).

47. McGeachy, M.J. et al. TGF-beta and IL-6 drive the production of IL-17 and $\mathrm{IL}-10$ by $\mathrm{T}$ cells and restrain $\mathrm{T}(\mathrm{H})-17$ cell-mediated pathology. Nat. Immunol. 8, 1309-1397 (2007).

48. Murphy-Ullich, J.E. \& Poczatek, M. Activation of latent TGF-beta by thrombospondin-1: mechanisms and physiology. Cytokin. Growth Factor Rev. 11, 59-69 (2000).

49. Noh, K.T. et al. Protein kinase $\mathrm{C} \delta(\mathrm{PKC} \delta)$-extracellular signal-regulated kinase 1/2 (ERK1/2) signaling cascade regulates glycogen synthase kinase-3 (GSK-3) inhibition-mediated interleukin-10 (IL-10) expression in lipopolysaccharide (LPS)-induced endotoxemia. J. Biol. Chem. 287, 14226-14233 (2012).

50. An, C.H. et al. TLR4 deficiency promotes autophagy during cigarette smoke-induced pulmonary emphysema. Am. J. Physiol. Lung Cell Mol. Physiol. 303, L748-L757 (2012). 